\title{
Pollution mapping of Yamuna River segment passing through Delhi using high-resolution GeoEye-2 imagery
}

\author{
S. Said ${ }^{1} \cdot$ A. Hussain ${ }^{2}$ \\ Received: 30 October 2017 / Accepted: 7 March 2019 / Published online: 16 March 2019 \\ (C) The Author(s) 2019
}

\begin{abstract}
River Yamuna is the largest tributary of river Ganges and has been acclaimed as a heavenly waterway in Indian mythology. However, 22-km segment of river Yamuna passing through Delhi from downstream of Wazirabad barrage up to Okhla barrage is considered as the filthiest stretch having been rendered into a sewer drain. The present study employs high-resolution GeoEye-2 imagery for mapping and monitoring pollution levels within the river segment by testing correlation between water quality parameters (WQPs) and the corresponding spectral reflectance values of the image. A total of 100 water samples collected from random sampling locations along the river segment were analyzed for $12 \mathrm{WQPs}$ in the laboratory and grouped into two classes, namely (WQP) organic $_{\text {and }}$ (WQP) $)_{\text {inorganic }}$. Several spectral band combinations as well as single bands were tested for any significant correlation with the two formulated WQP classes by performing multiple linear regression analysis. Results reveal that spectral band combination, i.e., $\{\overline{(R G B)} \times \sqrt{B / R}\}$, and the two formulated WQP classes exhibit strong positive correlation with $R=0.92$ and $0.91\left(R^{2} \sim 0.85\right.$ and 0.82 ; RMSE $\sim 1.03$ and 1.12) for calibration data and 0.85 and 0.84 (i.e., $R^{2} \sim 0.74$ and 0.72 ; RMSE $\sim 1.45$ and 1.64 ) for validation data, respectively. The spatial distribution maps depicting pollution levels of two WQP classes were generated in GIS framework, substantiating to the actual in situ pollution concentration levels in the river segment. The methodology adopted in the present study and results obtained validate the potential of high-resolution GeoEye-2 imagery for monitoring and mapping pollution levels in the water bodies.
\end{abstract}

Keywords Yamuna River · Water quality parameters (WQPs) $\cdot$ Multiple linear regression (MLR) $\cdot$ Spectral reflectance $\cdot$ Digital number $(\mathrm{DN}) \cdot$ Untreated wastewater

\section{Introduction}

River Yamuna originates from Yamunotri glacier in Himalayas and is the largest tributary of river Ganges in India. Along its entire traveling length of about $1380 \mathrm{~km}$, it passes through many states such as Himachal Pradesh, Uttar Pradesh, Uttarakhand, Haryana and Delhi. Almost around 60 million people depend for their livelihood on this river.

A. Hussain

athar.hussain@gov.in

S. Said

saif_said@rediffmail.com

1 Civil Engineering Department, Z.H. College of Engineering and Technology, Aligarh Muslim University, Aligarh, UP, India

2 Civil Engineering Department, Ch. Brahm Prakash Government Engineering College, Jaffarpur, New Delhi, India
There has been a radical change in Yamuna River water quality as it enters Delhi from Wazirabad barrage and leaves at Okhla barrage which is attributed to the fact that untreated wastewater from 17 small and big sewer drains is discharged directly into the river besides the largest Najafgarh industrial drain. Rapid urbanization and encroachments all along the flood plains of the river are also one of the causes for widespread surface water eutrophication and severe deterioration of the water quality.

Monitoring water quality is recognized as the first step toward understanding the characteristics of water pollution and devising effective mitigation strategies. The quality of water is referred by its physical, biological and chemical compositions. Chemical composition includes the organic and inorganic substances such as heavy metals, pesticides, detergents and petroleum. The physical composition comprises turbidity, color and temperature, whereas the biological composition includes plankton and pigments (Allee and Johnson 1999). In addition, some of the parameters 
that define the criteria for healthy river water and being widely analyzed in the water quality-based studies include $\mathrm{pH}$, turbidity, dissolved oxygen (DO), total suspended solids (TSS), total dissolved solids (TDS), turbidity, total hardness as $\mathrm{CaCO}_{3}$, biochemical oxygen demand (BOD), chemical oxygen demand (COD), calcium (Ca), magnesium $(\mathrm{Mg})$, alkalinity, phosphate $\left(\mathrm{PO}_{4}\right)$, sodium $(\mathrm{Na})$, potassium $(\mathrm{K})$, sulfate $\left(\mathrm{SO}_{4}\right)$ and nitrate $\left(\mathrm{NO}_{3}\right)$ to name a few. Monitoring and assessment of these water quality parameters require sampling from widely distributed locations, which is time-consuming and requires a lot of field and laboratory efforts to present statistical results (Shi et al. 2018; Nazeer and Nichol 2015; Singh et al. 2013; Duong 2012; Amandeep 2011; Kazi et al. 2009; Ekercin 2007; Icaga 2007; Wang et al. 2004; Silvert 1998; Pattiaratchi et al. 1994).

Traditionally, WQPs are obtained by procedural monitoring methods that involve extensive field sampling and costly laboratory analyses, which is time-consuming and can only be performed for relatively small areas (Song et al. 2012). Therefore, these limitations make traditional approaches difficult for overall and successive water quality forecasting at spatial scales (Chabuk et al. 2017; Panwar et al. 2015; Li et al. 2013). However, remote sensing in conjugation with geographic information system (GIS) provides better estimates and synoptic coverage of spatial distribution of pollution levels in rivers and water bodies at a relatively less field efforts and at a cheaper cost (Mishra and Patel 2001; Lindell et al. 1999; Dekker and Peters 1993). Optical remote sensing techniques are being widely used for monitoring water quality parameters such as turbidity, chlorophyll, temperature, suspended inorganic materials like sand, dust and clay, and dissolved organic matter (Allee and Johnson 1999; Fraser1998; Kondratyev et al. 1998; Pattiaratchi et al. 1994). Remote sensing satellite sensors quantify the measure of solar irradiance at varied wavelength bands reflected by the surface water, thereby providing spatial and temporal data that can be effectively employed in the analysis of variations in the surface water quality, requiring as precursor for adopting the strategies for sustainable management practices (Girgin et al. 2010; Dwivedi and Pathak 2007; Zhang et al. 2003; Ellis 1999; Fraser1998; Kondratyev et al. 1998; Chavez 1996; Pattiaratchi et al. 1994). The present study undertakes an attempt to monitor and map the spatial distribution of pollution levels corroborated by in situ samplings from selected locations along Yamuna River segment passing through Delhi while utilizing high-resolution GeoEye-2 imagery. WQPs were grouped into two classes in accordance with their chemical characteristics, and their sensitivity toward spectral reflectance band combinations was examined through MLR analysis. The study demonstrates a cost-effective methodology to monitor and map pollution levels in urban river segments as well as inland water bodies.

\section{Study area}

The present study covers a 22-km stretch of river Yamuna passing through Delhi, entering at Wazirabad barrage and leaving at Okhla barrage (Fig. 1), which is considered as an extremely polluted stretch of the entire river length. Delhi sprawls over $1483 \mathrm{sq} \mathrm{km}$ between latitude $28^{\circ} 34^{\prime} \mathrm{N}$ and a longitude of $77^{\circ} 07^{\prime} \mathrm{E}$ having an elevation of $213 \mathrm{~m}$ above the mean sea level and experiences heavy rains primarily during the monsoon season.

The river segment passing through the Delhi corridor constitutes merely $2 \%$ of the entire river length and accounts for nearly $76 \%$ of the total pollution that the river carries. Maximum discharge of untreated water at the downstream of Wazirabad barrage from several domestic and industrial drains including the largest Najafgarh and Hindon drains pollutes the segment to the extreme levels, thus rendering it unfit for any purpose. Little contribution of clean water is also made in this segment through Surghat, where Ganga and Yamuna water is provided for bathing purposes. This river segment branches out the Agra Canal at Okhla barrage, for fulfilling irrigation requirements in the states of Haryana and Uttar Pradesh. The river segment receives very little freshwater flow from Wazirabad barrage or even no flow all year round except during the monsoon period extending from July to September, which thereby reducing the dilution capacity of the segment.

\section{Materials and methods}

Water samples were collected from the mid-stream at a depth of $0.5 \mathrm{~m}$ on January 25, 2016, from the four selected sampling stations, namely Wazirabad barrage, ITO barrage, Nizamuddin bridge and Okhla barrage, wherein from each sampling station 25 water samples were collected from random locations, amounting to a total of 100 water samples from all four stations (Fig. 2a). The sampling stations selected were identified as point sources from where a large number of industrial and domestic drains directly dispose toxic effluents at the upstream and downstream of the sampling stations. Sampling stations comprising barrage structures are also served as water abstracting junctions where a maximum concentration of pollutants is mainly observed. Grab sampling procedure was adopted for the analysis of various water quality parameters as recommended by standard methods of analysis (APHA 1999). Samples were tested for $12 \mathrm{WQPs}$, namely TSS, TDS, $\mathrm{CaCO}_{3}, \mathrm{BOD}, \mathrm{COD}, \mathrm{Ca}$, $\mathrm{Mg}$, chloride $(\mathrm{Cl})$, ammonia $\left(\mathrm{NH}_{3}\right), \mathrm{K}, \mathrm{SO}_{4}$ and $\mathrm{NO}_{3}$. WQPs 
Fig. 1 Location map of the study area (map not to scale)
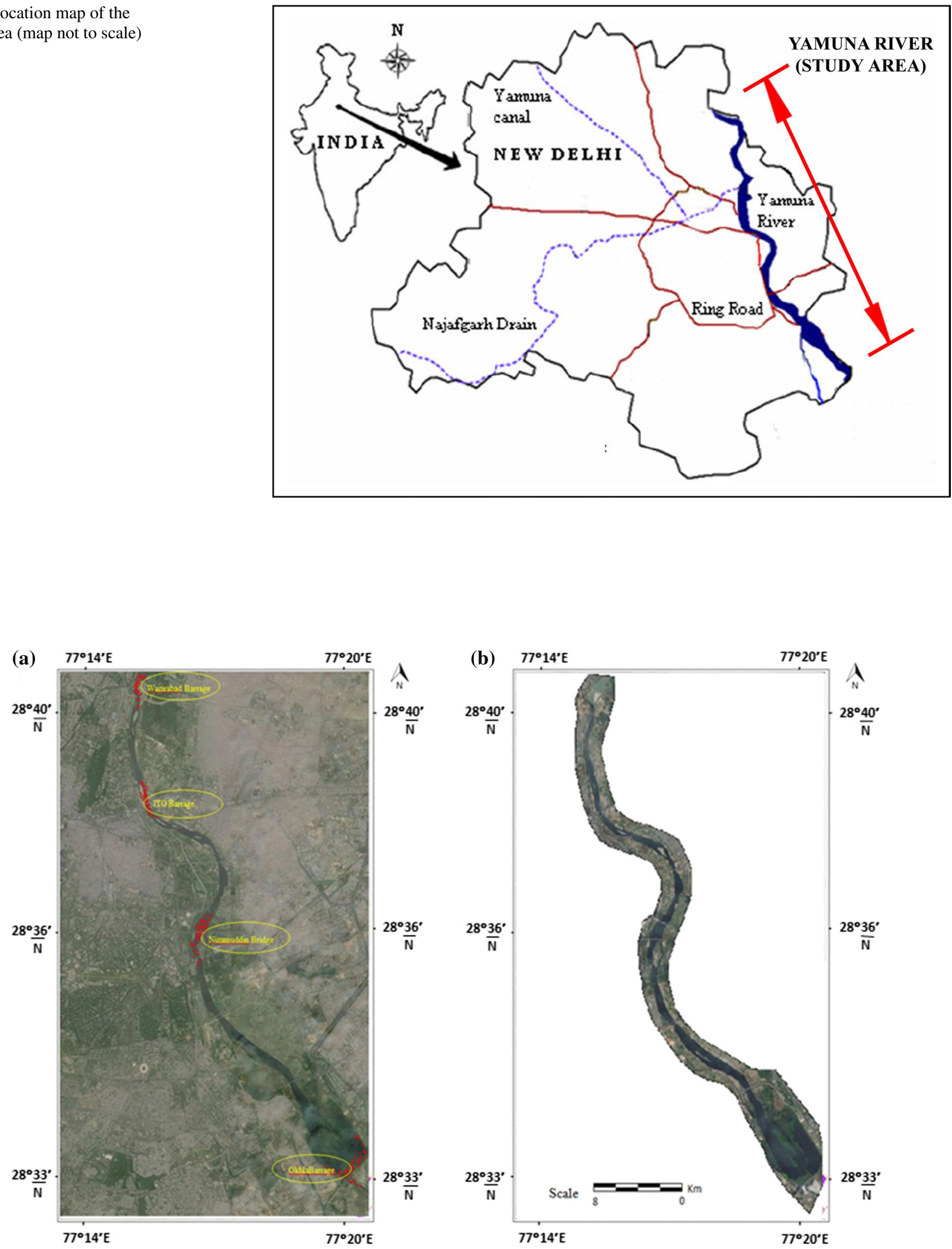

Fig. 2 a GeoEye-2 image of the study area depicting sampling locations marked with red dots. b Subset image of the study area 
were grouped in accordance with their chemical characteristics into two classes, namely (WQP) $)_{\text {organic }}$ and (WQP) inorganic $_{\text {. }}$ Grouping of WQPs under the classes was followed as below:

(a) (WQP) $)_{\text {organic }} \Rightarrow \mathrm{BOD}, \mathrm{COD}$ and TSS

(b) (WQP $)_{\text {inorganic }} \Rightarrow \mathrm{Cl}, \mathrm{SO}_{4}, \mathrm{NO}_{3}$, TDS,

$\mathrm{Ca}, \mathrm{Mg}, \mathrm{K}, \mathrm{NH}_{3}$ and $\mathrm{CaCO}_{3}$

GeoEye-2 satellite imagery of date January 25, 2016, concurrent to the water sampling date was employed in the study to monitor and map pollution levels within the $22-\mathrm{km}$ river segment. GeoEye-2 is a US-based satellite that collects images at a ground resolution of $1.34 \mathrm{~m}$ in the multispectral mode. Subset image of the study area was created in Erdas Imagine 9.3 (Fig. 2b).

Digital numbers (DN) from the four spectral bands (i.e., red, green, blue and NIR bands) corresponding to the point sampling locations were extracted and transformed to radiance values and then to the reflectance values before they were subjected to the analysis and interpretation. Conversion of $\mathrm{DN}$ values to radiance values removes the voltage bias and gains from the satellite sensor as described in Eq. 1. The radiance values were further converted to satellite reflectance values using Eq. 2. This conversion takes into account the varying sun angle due to differences in latitude, season and time of day, and the variation in the distance between the Earth and Sun. The conversion of DN values to radiance values and finally to reflectance values corresponding to sampling locations was carried out using Eqs. 1 and 2, respectively, which is proposed by Chander and Markham (2003):

$L_{\lambda}=\operatorname{Gain}_{\lambda} \times \mathrm{DN}_{\lambda}+$ offset $_{\lambda}$,

where $\lambda$ is the specific spectral band of image, NIR, red, green, blue or panchromatic, $L_{\lambda}$ is the spectral radiance for band $\lambda$ at the sensor's aperture $\left(\mathrm{mW} / \mathrm{cm}^{2} / \mu \mathrm{m} / \mathrm{str}\right), \operatorname{Gain}_{\lambda}$ is the radiometric calibration gain $\left(\mathrm{mW} / \mathrm{cm}^{2} / \mu \mathrm{m} / \mathrm{str} / \mathrm{DN}\right)$ for band $\lambda$ from product metadata, $D N_{\lambda}$ is the $\mathrm{DN}$ value for band $\lambda$ of image product, and offset ${ }_{\lambda}$ is the radiometric calibration offset $\left(\mathrm{mW} / \mathrm{cm}^{2} / \mu \mathrm{m} / \mathrm{str}\right)$ for band $\lambda$ obtained from product metadata.

$\rho_{P=\frac{\pi * L_{*} * d^{2}}{E_{\mathrm{SUN}} * \operatorname{Cos} \theta_{S}}}$,

where $\rho_{P}$ is the unit-less planetary reflectance, $d$ is the Earth-Sun distance (astronomical units), $E_{\mathrm{SUN} \lambda}$ is the mean solar exo-atmospheric spectral irradiances $\left(\mathrm{mW} / \mathrm{cm}^{2} / \mu \mathrm{m}\right)$, at an Earth-Sun distance of 1 astronomical unit (A.U.), $\theta_{s}$ is the solar zenith angle, and $L_{\lambda}$ is the spectral radiance for band $\lambda$ at the sensor's aperture ( $\left.\mathrm{mW} / \mathrm{cm}^{2} / \mu \mathrm{m} / \mathrm{str}\right)$. The Earth-Sun distance $(d)$ in astronomical units (A.U.) is obtained from GeoEye- 2 product manual. Correlations between four formulated WQP classes and reflectance values were explored for single bands as well as for several formulated band combinations. MLR analysis was performed using SPSS statistical software between single spectral bands as well as their combinations and WQP classes individually for evaluating and comparing the strength of correlation. The data set utilized in the analysis was combined for all four sampling stations that corresponded to a total of 100 samples of which 80 samples were utilized for calibration and the remaining 20 samples for validation purposes. Regression equations were formulated between the spectral band combinations exhibiting best correlation with WQP classes for the purpose of generating WQP maps in GIS framework.

\section{Results and discussion}

Water samples collected from four sampling stations were tested for 12 WQPs in the laboratory, and the descriptive statistics evaluated is summarized in Table 1. Water temperature along the river segment depicted relatively little fluctuations with values lying between 13 and $16{ }^{\circ} \mathrm{C}$, on account of chilling winter day. The $\mathrm{pH}$ values of collected water samples ranged from 7.7 to 7.9 , dwelling within the permissible range from 6 to 9 as prescribed by Central Pollution Control Board (CPCB), India. The abrupt increase in organic pollution content all along the river stretch downstream of Wazirabad barrage resulted in BOD levels lying far beyond the stipulated standards. Also, fluctuations in DO level from nil to well above saturation levels reflect the presence of organic pollution load and prevalence of eutrophic conditions (Tiwari and Shanmugam 2011). Altogether, 12 WQPs were found to be at the highest concentration levels exceeding the permissible limits far beyond as prescribed by $\mathrm{CPCB}$ throughout the river segment. Extremely high

Table 1 Range, mean and standard deviation of WQPs at sampling locations

\begin{tabular}{lllrc}
\hline S. no. & Parameters $(\mathrm{mg} / \mathrm{l})$ & Range min-max & Mean & \multicolumn{1}{c}{ SD } \\
\hline 1 & $\mathrm{BOD}$ & $4.55-45$ & 29.33 & 14.41 \\
2 & $\mathrm{COD}$ & $14.17-150$ & 100.66 & 48.93 \\
3 & $\mathrm{TSS}$ & $160-250$ & 209.77 & 23.51 \\
4 & $\mathrm{Cl}$ & $81.45-320$ & 198.34 & 88.09 \\
5 & $\mathrm{SO}_{4}$ & $47-119$ & 79.27 & 21.31 \\
6 & $\mathrm{NO}_{3}$ & $0.82-1.32$ & 1.07 & 0.146 \\
7 & $\mathrm{TDS}$ & $73.3-930$ & 384.69 & 278.99 \\
8 & $\mathrm{Ca}$ & $34.7-65$ & 49.03 & 9.07 \\
9 & $\mathrm{Mg}$ & $58.37-121$ & 86.35 & 23.82 \\
10 & $\mathrm{~K}$ & $8.5-29.6$ & 17.02 & 5.75 \\
11 & $\mathrm{NH}_{3}$ & $8.3-41.4$ & 21.93 & 9.97 \\
12 & $\mathrm{CaCO}_{3}$ & $331.5-661.7$ & 481.97 & 119.75 \\
\hline
\end{tabular}

$S D$ standard deviation 
pollution level is mainly associated with domestic and industrial sewage water draining into the river at short distances, whereby voluminous water abstraction at the upstream of Wazirabad barrage significantly reduces the dilution capacity of the entire river segment.

Results of MLR analysis employed to examine the strength of association between the two formulated WQP classes and spectral reflectance band combinations in terms of $R^{2}$ and RMSE values are presented in Table 2.

MLR analysis exhibits weak correlation for all band combinations as illustrated in Table 2, except for $\{\overline{(R G B)} \times \sqrt{B / R}\}$, yielding $R=0.92$ and $0.91\left(R^{2} \sim 0.85\right.$ and 0.82 ; RMSE $\sim 1.03$ and 1.12) for calibration data and 0.85 and 0.84 (i.e., $R^{2} \sim 0.74$ and 0.72 ; RMSE $\sim 1.45$ and 1.64) for validation data at $95 \%$ confidence level, respectively. Regression coefficients for spectral band combination $\{\overline{(R G B)} \times \sqrt{B / R}\}$ with the two formulated WQP classes are provided in Table 3.

Utilizing regression coefficients obtained from MLR analysis provided in Table 3, numeric values of each WQP class [i.e., $(\mathrm{WQP})_{\text {organic }}$ and $(\mathrm{WQP})_{\text {inorganic }}$ ] were computed for carrying out simple regression with $\{\overline{(R G B)} \times \sqrt{B / R}\}$ to obtain linear equations used for generating WQP maps in GIS framework. The regression equations obtained are provided below (i.e., Eqs. 3 and 4), and scatter plots are drawn as shown in Fig. 3a-d.

(a) $(\mathrm{WQP})_{\text {organic }}=1.264 \times\{\overline{(R G B)} \times \sqrt{B / R}\}-0.04371$

(b) $(\mathrm{WQP})_{\text {inorganic }}=1.483 \times\{\overline{(R G B)} \times \sqrt{B / R}\}-0.03776$.

WQP maps (Fig. 4) clearly demonstrate the pollution levels of WQPs in terms of organic and inorganic to be far beyond the permissible limits prescribed by CPCB throughout the entire length of the river segment. At some distance downstream of Wazirabad barrage, water quality reflected in the maps reveals low or minimum pollution levels due to the fact that there are no point or nonpoint sources of wastewater discharging into the river and is testified with the light color tones in WQP maps. Barely

Table 2 Coefficient of determination $R^{2}$ and RMSEs for spectral bands and their combinations for calibration data set

\begin{tabular}{llcllllllllll}
\hline Band combinations & Blue $(B)$ & Green $(G)$ & $\operatorname{Red}(R)$ & $\begin{array}{l}\text { Near infra- } \\
\text { red (NIR) }\end{array}$ & $\frac{B}{R}$ & $\frac{B}{\text { NIR }}$ & $\frac{G}{R}$ & $\overline{R G B}$ & $\overline{R G B} \times \sqrt{ }(B / R)$ & $\sqrt{ } \frac{B}{\text { NIR }}$ & $\frac{(\mathrm{NIR}-B)^{2}}{(\mathrm{NIR}+B)^{2}}$ \\
\hline \multirow{2}{*}{$\mathrm{WQP}_{\text {(organic) }}$} & $R^{2}$ & 0.12 & 0.09 & 0.23 & 0.18 & 0.32 & 0.56 & 0.51 & 0.58 & 0.82 & 0.57 & 0.59 \\
& $\mathrm{RMSE}$ & 12.6 & 16.7 & 8.8 & 10.7 & 8.5 & 4.4 & 3.9 & 7.6 & 1.12 & 6.5 & 4.2 \\
$\mathrm{WQP}_{\text {(inorganic) }}$ & $R^{2}$ & 0.08 & 0.10 & 0.29 & 0.21 & 0.37 & 0.48 & 0.45 & 0.56 & 0.85 & 0.49 & 0.54 \\
& $\mathrm{RMSE}$ & 23.4 & 9.1 & 8.2 & 9.3 & 6.3 & 5.6 & 5.8 & 11.7 & 1.03 & 6.8 & 3.6 \\
\hline
\end{tabular}

$\overline{R G B}$ : mean $R G B$ or $\{(R+G+B) / 3\}$

Table 3 Multiple linear regression coefficients and $R^{2}$ values for $\{\overline{(R G B)} \times \sqrt{B / R}\}$. Band combination with combined data of all sampling locations

\begin{tabular}{|c|c|c|c|c|c|}
\hline \multicolumn{6}{|c|}{$\begin{array}{l}\text { Multiple regression equation } Y=b_{\mathrm{o}}+b_{1} * X_{1}+b_{2} * X_{2}+b_{3} \\
\text { Where } Y=\{\overline{(R G B)} \times \sqrt{B / R}\} \\
\text { Data distribution: } 80 \% \text { correlation and } 20 \% \text { validation }\end{array}$} \\
\hline WQP class & Reg. Coeff & $\begin{array}{l}R^{2} \\
\text { calibration }\end{array}$ & $\begin{array}{l}\text { RMSE } \\
\text { calibration }\end{array}$ & $\begin{array}{l}R^{2} \\
\text { validation }\end{array}$ & $\begin{array}{l}\text { RMSE } \\
\text { validation }\end{array}$ \\
\hline$(\mathrm{WQP})_{\text {organic }}=\mathrm{BOD}, \mathrm{COD}$ and TSS & $\begin{array}{l}b_{0}=0.5972 \\
b_{1}=-0.0029 \\
b_{2}=-0.00084 \\
b_{3}=-0.00063\end{array}$ & 0.82 & 1.12 & 0.74 & 1.64 \\
\hline $\begin{array}{l}(\mathrm{WQP})_{\text {Inorganic }}=\mathrm{Cl}, \mathrm{SO}_{4}, \mathrm{NO}_{3}, \mathrm{TDS} \\
\mathrm{Ca}, \mathrm{Mg}, \mathrm{K}, \mathrm{NH}_{3} \text { and } \mathrm{CaCO}_{3}\end{array}$ & $\begin{array}{l}b_{\mathrm{o}}=0.3864 \\
b_{1}=-0.00023 \\
b_{2}=-0.00413 \\
b_{3}=-0.06821 \\
b_{4}=-0.05124 \\
b_{5}=-0.00425 \\
b_{6}=-0.00012 \\
b_{7}=-0.00362 \\
b_{8}=-0.07213 \\
b_{9}=-0.00513\end{array}$ & 0.85 & 1.03 & 0.72 & 1.45 \\
\hline
\end{tabular}


Fig. 3 Scatter plots of

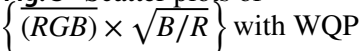
classes a calibration data $(\text { WQP })_{\text {organic }} \mathbf{b}$ validation data $(\mathrm{WQP})_{\text {organic }} \mathbf{c}$ calibration data $(\mathrm{WQP})_{\text {inorganic }} \mathbf{d}$ validation data $(\mathrm{WQP})_{\text {inorganic }}$
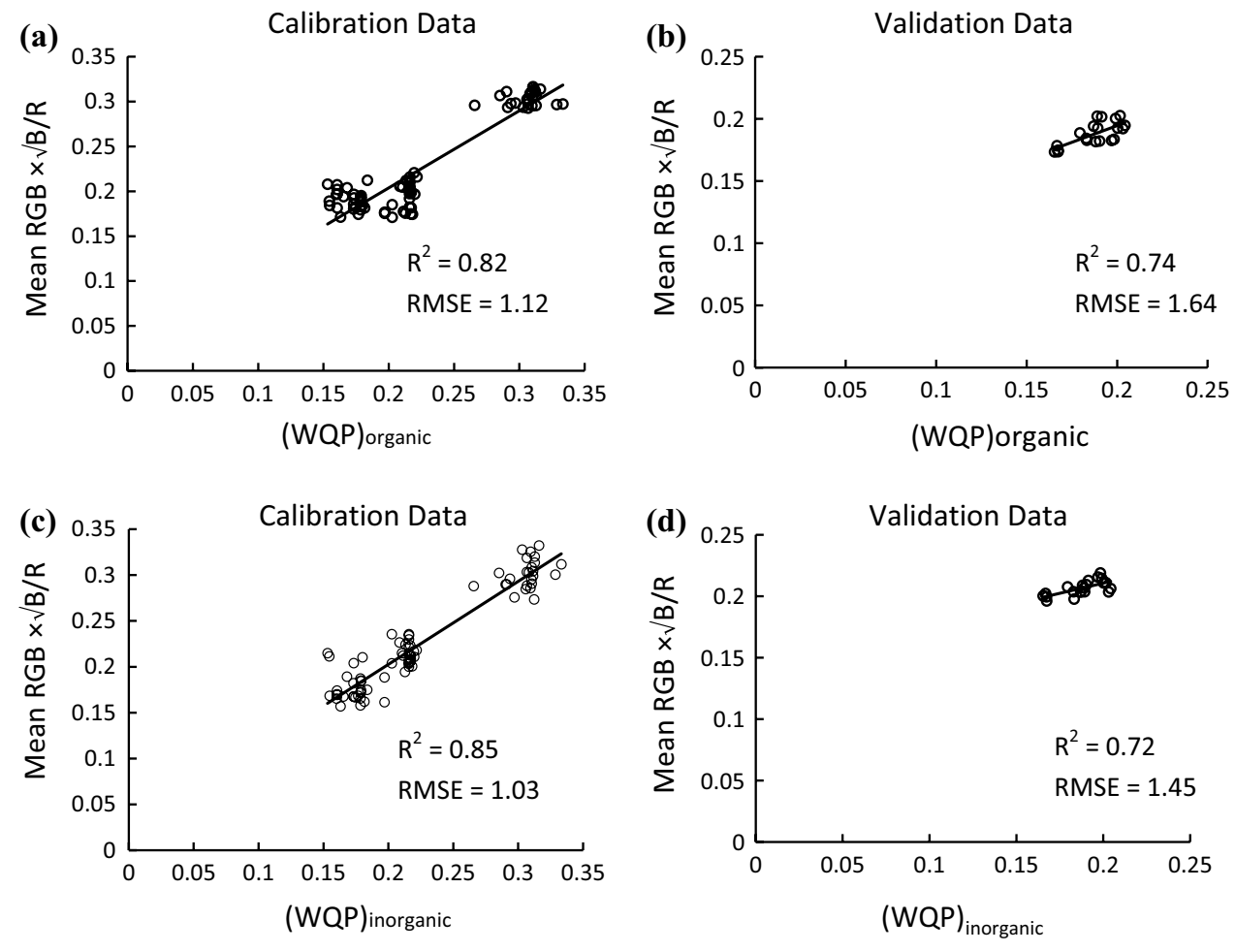
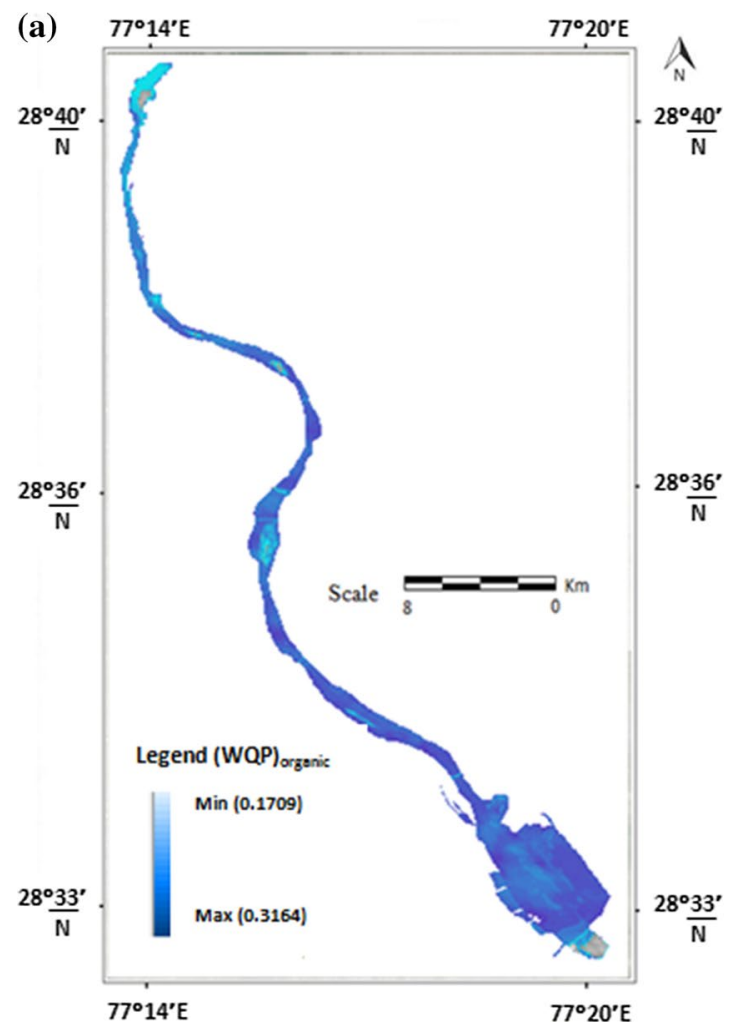

(b)
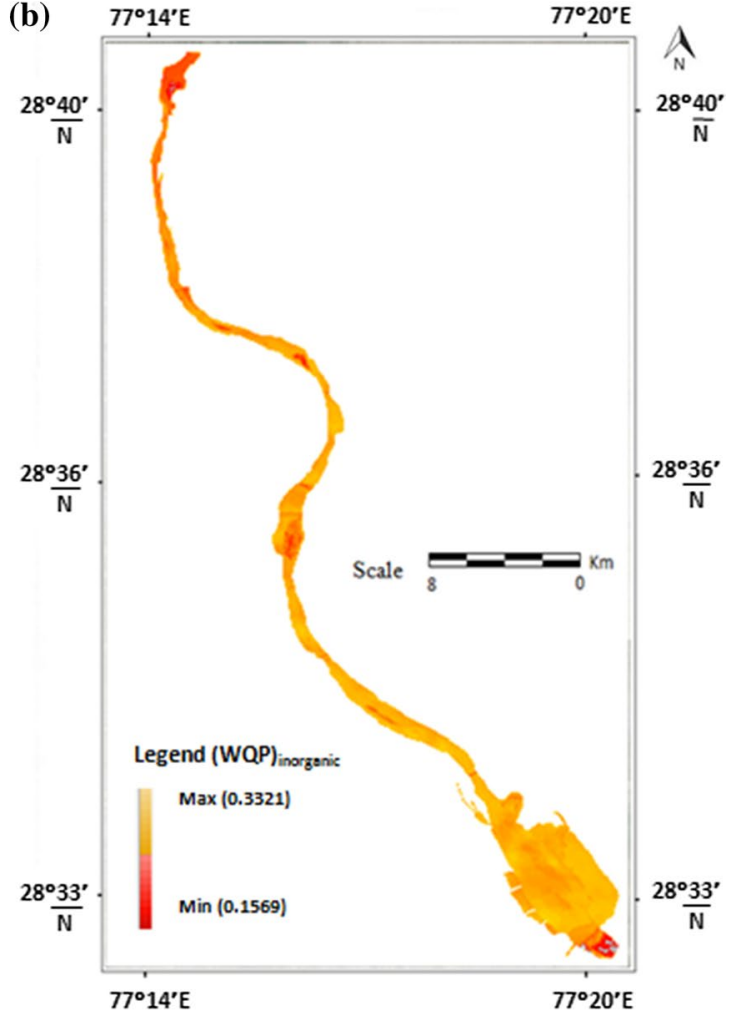

Fig. 4 WQP maps of the study area: $\mathbf{a}(\mathrm{WQP})_{\text {organic }}$ and $\mathbf{b}(\mathrm{WQP})_{\text {inorganic }}$ 
$500 \mathrm{~m}$ downstream of Wazirabad barrage, Najafgarh drain joins the river stream, thereby causing abnormally high pollution concentrations owing to the heavy release of industrial effluents as well as domestic sewage, which is also considered as a starting point of river contamination. Moving downstream of Najafgarh drain, pollution level increases extremely far beyond the permissible limits because many more major sewer drains (approx. 25 drains) are discharged directly into the river as evidenced by darker color tones along the entire river reach in the WQP maps. The above observation can also be attributed to the fact that the point sampling and analysis were carried out during the winter season (i.e., January 25, 2016), wherein pollutant concentrations are at the highest levels due to negligibly low river flows.

\section{Conclusions}

The present study utilizes high-resolution GeoEye-2 imagery for monitoring and mapping pollution levels within 22-km Yamuna River segment passing through the Delhi City. A total of 100 water samples collected were tested for 12 WQPs that were grouped into two broad classes, namely (WQP) $)_{\text {organic }}$ and (WQP) $)_{\text {inorganic }}$. Several spectral band combinations as well as single bands were examined for any positive or negative correlation with the two formulated WQP classes through MLR analysis. Results revealed that band combination, i.e., $\{\overline{(R G B)} \times \sqrt{B / R}\}$, exhibited strong correlation with both the WQP classes as compared to the rest of band combinations, i.e., $R=0.92$ and 0.91 for calibration data and 0.85 and 0.84 for validation data, respectively. WQP maps apparently testify the lowest pollution levels in terms of all WQPs at Wazirabad sampling station as depicted by the light color tones and high pollutant concentration all along the river segment as exhibited by the darker tones. The study, however, demonstrates the potential of GeoEye-2 imagery for monitoring and mapping pollution levels in the water bodies that may find its usefulness for sustainable planning and management of surface water resources. The pollution level map of the river segment prepared by employing the proposed methodology can be applied to all surface water bodies; however, temporal variation in pollution levels during pre- and post-monsoon seasons can be addressed in future studies so as to formulate appropriate measures for rejuvenating the dead river segment.

Acknowledgements Author gratefully acknowledges the anonymous reviewers for constructive comments and suggestions for improvement in the draft.
Open Access This article is distributed under the terms of the Creative Commons Attribution 4.0 International License (http://creativeco mmons.org/licenses/by/4.0/), which permits unrestricted use, distribution, and reproduction in any medium, provided you give appropriate credit to the original author(s) and the source, provide a link to the Creative Commons license, and indicate if changes were made.

\section{References}

Allee RJ, Johnson JE (1999) Use of satellite imagery to estimate surface chlorophyll a and Secchi disc depth of Bull Shoals Reservoir, Arkansas, USA. Int J Remote Sens 20(6):1057-1072

Amandeep V (2011) Identification of land and water regions in a satellite image: a texture based approach. Int J Comput Sci Eng Technol (IJCSET) 1:361-365

Chabuk A, Al-Ansari N, Hussain HM, Knutsson S, Pusch R, Laue J (2017) Combining GIS applications and method of multi-criteria decision-making (AHP) for landfill siting in Al-Hashimiyah Qadhaa, Babylon, Iraq. Sustainability 9:19-32

Chander G, Markham B (2003) Revised Landsat-5 TM radiometric calibration procedures and post calibration dynamic ranges. IEEE Trans Geosci Remote Sens 41:2674-2677

Chavez PS (1996) Image-based atmospheric corrections revisited and improved. Photogramm Eng Remote Sens 62:1025-1036

Dekker AG, Peters SWM (1993) The use of the Thematic Mapper for the analysis of eutrophic lakes: a case study in the Netherlands. Int J Remote Sens 14(5):799-821

Duong DN (2012) Water body extraction from multi spectral image by spectral pattern analysis. J Photogramm Remote Sens Spat Inf Sci Melb XXXIX-B8:248-259

Dwivedi SL, Pathak VA (2007) Preliminary assignment of water quality index to Mandakini river, Chitrakoot. Indian J Environ Prot 27:1036-1038

Ekercin S (2007) Water quality retrievals from high resolution IKONOS multispectral imagery: a case study in Istanbul, Turkey. Int J Environ Pollut 183(4):239-251

Ellis JB (1999) Impacts of urban growth on surface water and groundwater quality. Birm Int Assoc Hydrol Sci (IAHS) 34:118-121

Fraser RN (1998) Multispectral remote sensing of turbidity among Nebraska Sand Hills Lakes. Int J Remote Sens 19(15):3011-3016

Girgin S, Kazanci N, Dügel M (2010) Relationship between aquatic insects and heavy metals in an urban stream using multivariate techniques. Int J Environ Sci Technol 7(4):653-664

Icaga Y (2007) Fuzzy evaluation of water quality classification. Ecol Indic J-Elsevier 7:710-718

Kazi TG, Arain MB, Jamali MK, Jalbani N, Afridi HI, Sarfraz RA, Baiga JA, Shaha Abdul Q (2009) Assessment of water quality of polluted lake using multivariate statistical techniques: a case study. Ecotoxicol Environ Saf J 72:301-309

Kondratyev KY, Pozdnyakov DV, Pettersson LH (1998) Water quality remote sensing in the visible spectrum. Int J Remote Sens 19:957-979

Li J, Liu HX, Li YC, Mei K, Dahlgren R, Zhang MH (2013) Monitoring and modeling dissolved oxygen dynamics through continuous longitudinal sampling: a case study in Wen-RuiTang River, Wenzhou, China. Hydrol Process (IAHS) 27:3502-3510

Lindell T, Pierson D, Premazzi G, Zilioli E (1999) Manual for monitoring European lakes using remote sensing techniques EUR 18665 EN, Official Publications of the European Communities, Luxembourg, pp 161-178

Mishra PC, Patel RK (2001) Study of the pollution load in the drinking water of Rairangpur; a small tribal dominated town of North Orissa. Indian J Environ Ecoplann 5(2):293-298

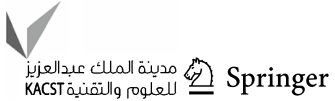


Nazeer M, Nichol JE (2015) Combining landsat TM/ETM + and HJ-1 A/B CCD sensors for monitoring coastal water quality in Hong Kong. IEEE Geosci Remote Sens Lett 12(9):1898-1902

Panwar A, Bartwal S, Dangwal S, Aswal A, Bhandari A, Rawat S (2015) Water quality assessment of River Ganga using remote sensing and GIS technique. Int J Adv Remote Sens GIS 4(1):1253-1261

Pattiaratchi CB, Lavery P, Wyllie A, Hick P (1994) Estimates of water-quality in coastal waters using multi-date Landsat Thematic Mapper data. Int J Remote Sens 15:84-1571

Shi L, Mao Z, Wang Z (2018) Retrieval of total suspended matter concentrations from high resolution WorldView-2 imagery: a case study of inland rivers. In: IOP conference series: earth and environmental science, vol 121, p 032036

Silvert W (1998) Fuzzy indices of environmental conditions. In: INDEX workshop on environmental indicators and indices, St. Petersburg, Russia

Singh A, Jakubowski AR, Chidister I, Townsend PA (2013) A MODIS approach to predicting stream water quality in Wisconsin. Remote Sens Environ 128:74-86
Song KS, Li L, Li S, Tedesco L, Hall B, Li LH (2012) Hyperspectral remote sensing of total phosphorus (TP) in three central Indiana water supply reservoirs. J Water Air Soil Pollut 223:1481-1502

Tiwari S, Shanmugam P (2011) An optical model for the remote sensing of colored dissolved organic matter in coastal/ocean waters. Estuar Coast Shelf Sci 93:396-402

Wang YP, Xia H, Fu JM, Sheng GY (2004) Water quality change in reservoirs of Shenzhen, China: detection using LANDSAT/TM data. Sci Total Environ 328:195-206

Zhang Y, Pulliainen JT, Koponen SS, Hallikainen MT (2003) Water Quality Retrievals from Combined Landsat TM Data and ERS-2 SAR Data in the Gulf of Finland. IEEE Trans Geosci Remote Sens 41:622-629

Publisher's Note Springer Nature remains neutral with regard to jurisdictional claims in published maps and institutional affiliations. 